\title{
Travel live streaming: an affordance perspective
}

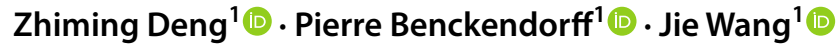

Received: 14 August 2020 / Revised: 28 February 2021 / Accepted: 9 March 2021 /

Published online: 15 March 2021

(c) The Author(s), under exclusive licence to Springer-Verlag GmbH Germany, part of Springer Nature 2021

\begin{abstract}
This study draws on tourism literature and current examples to propose that the emergence of Travel Live Streaming (TLS) provides new affordances for live streamers, viewers, and sponsors. Despite its increasing popularity and the new opportunities for communication and marketing in tourism, TLS has received limited attention in the academic literature. The aim of this paper is to use affordances theory to understand some of the key features and benefits of TLS. It is argued that TLS affordances include temporal, spatial, interactive, and media affordances. These affordances support new opportunities and actions for travel live streamers, viewers, and sponsors. The paper proposes an affordance-based TLS framework and concludes with three propositions to guide future research directions.
\end{abstract}

Keywords Travel live streaming · Affordance $\cdot$ Tourism experience $\cdot$ Interaction · Performance $\cdot$ Information and Communication Technologies (ICTs)

\section{Introduction}

Live streaming has been defined as individuals (broadcasters) recording and broadcasting video in real time, enabling multi-modal (video, image and text) interactions between live streamers and viewers (Hu et al. 2017). Live streaming combines video and audio with online platforms that allow content creators to broadcast in real time while engaging with viewers through synchronous interactions between live streamers and viewers (Thorburn 2014). In a culture obsessed with 'nowness' (Buhalis and Sinarta 2019), live streaming is becoming increasingly prevalent on many social networking sites (e.g., Facebook Live, Twitch, TikTok). Recent research has begun to explore the marketing applications of live streaming (Wongkitrungrueng et al. 2020). In the tourism field, live streaming is increasingly used by social media influencers (SMIs), travel bloggers, travel agents and tourism destinations as a new channel for creating and circulating

Zhiming Deng

z.deng@business.uq.edu.au

1 UQ Business School, University of Queensland, Brisbane, QLD 4072, Australia 
travel experiences, selling products, or promoting destinations. This has led to the emergence of 'travel live streaming' (TLS), where content creators use live streaming to broadcast their tourism activities, capture destination landscapes, and interact with others in real time.

TLS is gaining the attention of tourism destinations (e.g., the Melbourne Remote Control Tourist Campaign), online travel agencies (e.g., C-trip), and several social media platforms. Hard hit by the 2020 COVID-19 pandemic, some sectors of the tourism industry have employed TLS to keep potential travellers engaged. For instance, in lieu of actual experiences, Tourism Australia launched 'Live from Aus.' to live stream tourism experiences across social media channels (Tourism Australia 2020). Similarly, China's largest online travel company, Trip. com, initiated 'Boss Live Session' hosted by the co-founder, James Liang to promote domestic travel. One of his live streams at Sanya generated USD 1.4 million advance purchases for accommodation within one hour (Zhu 2020). Despite the increasing significance of live streaming in the tourism industry, the topic has not received a careful and systematic exploration in terms of what constitutes TLS.

While TLS can be studied from many perspectives, affordance theory offers a useful way to initially explore the topic. The notion of affordances was originally derived from ecological psychology to describe how the properties of an object or environment can be used to support the actions of individuals (Gibson 1979; Norman 1988). Affordance theory has been recognised as a useful perspective for describing how individuals use technological artefacts (Blewett and Hugo 2016; Hutchby 2001), depending on users' characteristics, goals and context of use (Leonardi 2012). The tourism literature has recently adopted affordance theory to consider human-environment interactions (Chen and Wu 2021), and human-computer interfaces (Lei et al. 2019).

This paper adopts the position that the use of live streaming is a socio-technological phenomenon that depicts the relationship between participants' social behaviours (e.g., live streamer-viewers interaction) and the technological environment (Lu et al. 2019). Cabiddu et al. (2014) pointed out that affordances are a powerful means to study socio-technical phenomena. The affordance lens thus provides an analytical tool to broaden the understanding of live streaming in tourism. In this study, we specifically focus on identifying TLS affordances and how these affordances provided abilities for TLS participants. For instance, travel live streamers can create authentic tourism-related content, viewers can interact in real time with travel live streamers, and sponsors can realise strategic and operational goals. We therefore define TLS as an interactive form of socio-technical practice characterised by the real-time production and consumption of visual tourism media through a live streaming platform.

To understand what TLS involves, the objectives of this study are to: (1) apply affordance theory to analyse TLS; (2) ascertain how TLS participants behave through their afforded actions when involved in TLS; and (3) develop an affordance-based framework to show the relationships between TLS participants. The paper concludes with several propositions and opportunities for future research. 


\section{Live streaming and TLS}

\subsection{Live streaming and its application}

Traditionally, live streams were limited to television broadcasts; however, recent advances in technology (e.g., video compression algorithms, data transformation systems) have supported the development of live streaming as a new form of visual communication through social media platforms (e.g., Facebook Live, YouTube Live, and TikTok). Like most trending phenomena, live streaming has been applied to a range of research contexts. Examples include game streaming (Kaytoue et al. 2012; Taylor 2018), live streaming e-commerce and service (Scheibe et al. 2016; Wongkitrungrueng and Assarut 2018), and e-sports (Burroughs and Rama 2015). However, the scope of these studies focused mainly on the technical structure of live streaming, with some exceptions that focused on social foundations which might explain the mechanisms of live streaming (Hilvert-Bruce et al. 2018; Lim et al. 2020). Another line of research examined the content creators (live streamers) and viewers by exploring participatory culture (Zhou et al. 2019), viewers motivations for watching (Todd and Melancon 2018), and gift-sending behaviour (Yu et al. 2018).

\subsection{Travel Live Streaming (TLS)}

Rather than a single technology, TLS is a mix of different types of technology that integrate several media forms. With the affordances and ubiquity of mobile devices (e.g., smart phones and mobile apps), live streamers can stream content from any location and engage with physical environments. Typical TLS involves a travel live streamer who documents travel experiences in real time through a live streaming channel or social media platform. Viewers using the live channel can interact with the travel live streamer contemporaneously. For example, Lu et al. (2019) investigated outdoor live streaming using the Chinese online platform, Douyu, to understand user experiences, such as hiking and fishing. Given its unique features (realtime viewing experience and interaction), TLS has gained popularity on major social media platforms (e.g., Facebook, Instagram, YouTube). Several tourism destinations and organisations have used TLS as a marketing or business tactic. For example, hotel chain (e.g., Accor) employs live streaming as a 'visual doorway to a tourist's attention' to promote services and products. In China, live streaming has also penetrated the tourism industry and become popular among social media platforms (e.g., TikTok). Despite being increasingly adopted by the tourism industry, particularly in Asian destinations (e.g., China, South Korea, and Japan), academic research has paid little attention to TLS.

While live streaming is not novel, new insights can be identified by exploring how it is applied in the tourism context. Sjöblom et al. (2019) pointed out that the live streaming platform, Twitch, provides distinct affordances through technology, interaction, and specific environments. This study adopts a similar perspective to 
argue that participants (travel live streamers, viewers, and sponsors) are able to articulate different actions informed by TLS affordances. Affordances need to be perceived by participants to realise prospects (Norman 1988). Clarifying, interpreting and integrating TLS affordances extends participants' needs to move beyond the basic premise that live streaming allows streamers to broadcast themselves while travelling. The following sections discuss affordance theory and identifies specific TLS affordances for different groups of users.

\section{Affordance Theory}

In the ecological psychology literature, affordance theory in its broadest sense explains how an environment provides possibilities for users' actions (Gibson 1979). This notion simultaneously considers the affordances of artefacts (e.g., a mobile app) and of the animal-environment system (e.g., a fish and river) (Norman 1988). After the notion of affordances was initially developed by psychologists, was quickly appropriated in other fields. For example, affordance theory is useful to direct service design to enhance customer interaction (Sun et al. 2019); it is also useful to accomplish innovation in tourism organizations through social media (Buckley and Akhoundogli 2020). Therefore, affordance theory offers the means to interpret and guide potential actions.

Within tourism literature, affordances can be generally categorised into several lines of inquiry. The first analysis aligns with the original definition of affordances in psychology to examine places affording tourist behaviours. For example, Baerenholdt et al. (2004) investigated how the beach affords tourists with actions, such as swimming and building sandcastles. The second line of inquiry adopted this theoretical lens when investigating digital technology and social media use. For instance, Cabiddu et al. (2014) investigated social media affordances for tourism organisations to engage customers. Similarly, Lei et al. (2019) utilised technology affordance theory to compare hoteliers' and customers' perceptions of branded hotel mobile apps. More recently, affordance theory has been applied to tourism research as an analytic approach (Fesenmaier and Xiang 2017; Tomej and Xiang 2020). These studies support the importance of affordance perspective to provide theoretical and practical insights into the tourism industry.

This paper builds on previous work by using affordance theory as an ontological lens for identifying the existence of affordances that enable the behaviours of three groups of TLS participants. These affordances emerge from an amalgam of different technological advances in areas such as mobile video capture and compression, storage, transmission, connectivity, and social media.

\section{Conceptual development}

Building explanations not only helps researchers to understand the phenomenon but also assists to establish theoretical understandings to advance a related field (Shaw et al. 2018). Based on a literature review that compared emergent concepts, 
constructs, and theories (Levy and Ellis 2006), this paper employed a conceptual systematic approach to describe important concepts and their theoretical relationships (Wacker 1998). The paper draws together three aspects: (1) live streaming and TLS; (2) affordance theory and its theoretical foundations underlying TLS affordance; and (3) TLS affordances that enable TLS participants' behaviours. The conceptual systematic approach is useful for developing propositions for future research (Rossi et al. 2018).

The extant literature on live streaming (e.g., Hu et al. 2017; Sjöblom et al. 2019) and concepts that inform the affordance perspective, such as affordances of social media (e.g., Cabiddu et al. 2014), and digital mediated technologies (e.g., Dinhopl and Gretzel 2015, 2016) are used in this paper to develop theoretical foundations. Based on this analysis, it is proposed that the technologies which underpin TLS result in four important affordances dimensions: temporal, spatial, interactivity, and media affordances.

\subsection{Temporal affordance}

Temporal affordance describes the real-time TLS production and consumption by travel live streamers and viewers. Advances in ICTs (e.g., internet connectivity, digital devices) allow travel live streamers to stream their travel experiences from any location at any time. As Zou (2018) noted, leisure time becomes work time as live streaming occurs in an interactive and collaborative environment wherein live streamers are constantly contributing content and value. Similarly, Agger (2011) proposed that the advent of smartphones creates a different mobility of time, 'iTime', which alters the pre-internet boundaries between public and private, day and night, work and leisure. On the other hand, the temporal affordance of TLS is more efficient and richer in meaning in that it allows viewers to watch what travel live streamers are doing at the tourism destination in real-time. Viewers are offered opportunities to organise their viewing schedule and picking the content they want to consume from a range of publishers, networks and formats (Recktenwald 2017).

It is important to note that this temporal affordance only exists while a travel live stream is being produced and consumed in real-time. If the live stream is made available as a recording after the live streaming event has concluded, this temporal affordance is transformed into a persistence affordance, as discussed in the body of scholarly literature on social media affordances (Cabiddu et al. 2014; Treem and Leonardi 2013). Persistence affordance emphasises that the information can be saved and stored over time, but temporal affordance highlights the distinction of TLS from other visual media technologies commonly employed in tourism contexts.

\subsection{Spatial affordance}

Spatial affordance refers to the capacity to integrate multiple spaces to create a hybrid TLS environment. Digital technology brings about a technological change in communication and interaction, and offers an ensemble of shifting and fluid experiences in place and space (Jovicic 2019). Dux and Kim (2018) argued that live 
streaming serves as a virtual 'third place' where communities form and grow, with viewers using chat rooms to converse, laugh, and joke with each other about content they are watching. The activities organised around people nearby or locationbased virtual groups, eventually turn all spaces into objects of social production. Unlike many other forms of live streaming (e.g. gaming and service) (Li and Peng 2021; Sjöblom et al. 2019), travel live streamers exhibit elements of their experience in public spaces (e.g. tourism destinations), rather than private spaces, such as the home. TLS is therefore a real-time event set within several online and offline spaces, including the physical site of the tourism destination, the virtual TLS environment itself, and the digital host of the TLS.

\subsection{Interactivity affordance}

Interactivity affordance is related to the way social media is used to enable the communication and engagement capacity of TLS. TLS has gradually become integral to many social media platforms with social media being a 'digital heaven' for tourism (Leung et al. 2013). The literature points out that social media acts as a space where people follow, share, rate and discuss tourism-related content (Leung et al. 2013), thus creating personalised and contextualised experiences (Buhalis et al. 2019). Further, the social media affordance of social connectivity provides users with large and instant audiences (Bucher and Helmond 2017).

TLS's streamers can use the content-sharing affordance of social media to create, share, and connect with viewers. Travel live streamers may use hashtags as a signalling cue in a travel live stream's title (e.g., \#traveltoparis). This affordance can help travel live streamers to accumulate more viewers and followers. Viewers are also able to interact with a travel live streamer through the social interactivity affordance of social media. Notably, the interactivity affordance of TLS emphasises the realtime interaction between travel live streamer and viewers, and also offers viewers the ability to direct the travel live streamer's activity. In other words, TLS often requires the live streamer and viewers to cooperate to create experiences through real-time interaction. A typical example of this is when viewers direct a live streamer to experience a specific place or product.

These observations inform how TLS is being supported by social media. This study draws on the social media affordance literature to argue that: (1) social media is not only an outlet for travel live streamers to post content but also a platform for TLS participants to be connected; (2) TLS can be viewed as a product where the boundaries of tourism experience are negotiated and challenged to establish a new genre of interactive digital tourism.

\subsection{Media affordance}

Media affordances enable two behaviours in the TLS context: (1) the ability for travel live streamers to produce TLS content and communicate with viewers; and (2) the ability for viewers to make text comments and watch and listen to TLS content. 
TLS media affordances also involve the use of visual media, such as video, photos, text, and emoticons.

The act of travelling has long correlated positively with a proliferation of visual media. Scholars have explored the role of visual media in tourist experiences and social relationships produced using digital technology, such as photography and videography (Haldrup and Larsen 2003; Scarles 2009). Research has clarified the importance of visual media in affording tourist experiences. For example, while photography has dominated travellers' representations of the tourist experience (Lo et al. 2011), videography is essential for capturing travellers' visual representation of recreation (Dinhopl and Gretzel 2016). Whereas TLS is closely connected to tourist photography and videography, it is not simply a progression of these visual media. Although research into visual media offers valuable affordances for understanding TLS, the media affordances that differentiate TLS from photography and videography need to be acknowledged.

TLS media affordances are consistent with the affordances of visual media regarding the use of visual cues to present content. For instance, literature addresses the vital role of visual media in representing the tourist experience (Dinhopl and Gretzel 2015; Terzidou et al. 2018), although the emphasis has remained on asynchronous posts of static images or videos. A feature of TLS is its ICT-enabled affordance to present the visual continuity of the experience in real time, alongside synchronous interaction to orient content presentation. This is distinct from tourist photography and videography, which present visual cues from the past that produce digital encounters of specific times selected during production (Dinhopl and Gretzel 2015). Further, the unedited nature of TLS content contrasts with photo and video content, which is often subjected to filtering and further editing. The unpredictability of encounters with real-time environments, people and activities imbues TLS content with authentic visual cues about the destination or tourist experience. It can thus be argued that TLS is not simply a visual medium; it also provides a space for embodied visualities, simultaneous communication and interaction for representing touristic activities. Table 1 contrasts TLS with photography and videography.

Having identified four key TLS affordances, it is necessary to further consider how these affordances support the goals and actions of TLS participants. Affordance can be varyingly perceived by different users with different goals and users may change the affordance accordingly as they use it (Reed 2014). This is particularly evident in tourism where activities are dynamic and involve different participants for various purposes (Camisón and Monfort-Mir 2012). The following section

Table 1 Comparison of TLS with existing visual media

\begin{tabular}{lll}
\hline Photography & Videography & Travel live streaming (TLS) \\
\hline Static moments & Visual continuity & Visual continuity in real time \\
Text-to-text interaction & Text-to-text interaction & Synchronous face-to-text interaction \\
Edited content & Edited content & Unedited content \\
Mediated experience & Mediated experience & Mediated/co-created experience \\
\hline
\end{tabular}


exemplifies TLS participants and explores how their actions may enabled by TLS affordances.

\section{Actions and goals enabled by TLS affordances}

TLS participants involve travel live streamers, viewers, and sponsors. As the preceding sections have mentioned, affordance theory suggests that participants may hold different perceptions of TLS's functions and their context-based interactions with TLS. This section illustrates how different groups of participants can use TLS affordances to support their goals and actions.

\subsection{Travel live streamers}

Travel live streamers are broadcasters who create live streaming content during their travels. Everyone can create a live stream or watch a live streamer travelling from thousands of kilometres away because advances in technology infrastructure (e.g., mobile devices and fast Internet speeds) enable them. Not every travel live streamer can become a SMI, because popularity is not only driven by technology, but also by many other individual or social reasons. Despite this, TLS affordances have created great opportunities for live streamers to construct social identity, perform, and engage in storytelling.

\subsubsection{Social identity}

Social identity depicts intergroup behaviours and human social identity (Stets and Burke 2000). It can lead people to differentiate themselves from others by their different attributes (e.g., perceptions, attitudes). TLS enables live streamers to construct a social identity that enhances viewers' participation (Hu et al. 2017). During the process, live streamers can communicate with viewers by presenting shared personal attributes such as personality, competence, and knowledge. Media affordances allow travel live streamers to present their social identity by capturing fleeting moments to present the self. Furthermore, interactivity affordances provide travel live streamers with opportunities to interact with viewers and sponsors. This process is also shaped by a travel live streamers' personality, beliefs, tastes, and attitudes conveyed through real-time interactions. Examples of social identity include social media influencers showing their personality (e.g., humour), rich travel experiences, and knowledge to characterize their TLS contents and attract viewers. Presenting social identity through TLS affordances raises question about how live streaming technology empowers individuals to play different roles in the online community.

\subsubsection{Performativity}

In gaming contexts, live streamers are performers who play a central role in the live stream (Walker 2014; Woodcock and Johnson 2019). Zhao et al. (2018) 
claimed that live streamers attract viewers with their appearance, performance, and conversation, in exchange for mental satisfaction, self-esteem and monetary returns. In TLS, the performance involves anecdotes related to the physical tourism destination. TLS streamers physically visit a destination, participate in touristic live streaming activities, share travel experiences, and perform to satisfy viewers' need for novelty and unexpected social interaction. The connection with viewers places live streamers in the simultaneous role of performers in, and narrators of, the tourist experience. In other words, TLS streamers behave more like those who perform than those who mediate, by presenting their self in front of the camera.

Goffman's (1978) dramaturgy claims that individuals involved in the daily performance to present self are bounded in time and space. While in touristic photography studies, the travelling self is the performer (Larsen 2005), and performance can take place whenever social activity is engaged. Similarly, in TLS settings, TLS is a real-time activity in a blended space (i.e., the physical setting of destinations and the virtual live streaming environment). Once the activity starts, the TLS streamer performs by showcasing the view, streaming their activities at the destination, and interacting with unexpected strangers. The affordances of the technology offer a virtual stage for live performance. In tourism, the notion that live streaming is a performance raises questions about how the performers render, negotiate, or manage authentic content for viewers, as well as the extent to which they perform their real self.

\subsubsection{Storytelling}

Visual media research acknowledges that photography and videography support storytelling (Dinhopl and Gretzel 2016). It represents the experience while also enabling the creation of tourist experience narratives that emerge as embodied performance through digital storytelling. When TLS streamers produce and share content with their viewers on social media, they are in essence all storytellers who perform socially by sharing stories. The temporal affordances of TLS enable travel live streamers to share stories in real-time. However, an important research question is whether this temporal affordance results in storytelling that is authentic, improvised, and spontaneous, rather than scripted.

\subsection{TLS viewers}

The TLS viewers, that is, those who watch a specific live streamer travelling, are integral to the co-creation of tourist experiences with live streamers. Viewers interact and comment through chat streams while watching/monitoring TLS activities. New technology allows viewers to virtually experience and access a destination before (or even without) travelling there. For viewers, TLS affordances support their needs to seek information, engage socially and be socially present. 


\subsubsection{Information seeking}

On social network sites (SNS), users have the visibility affordance to effortlessly access information about someone else, or information usually difficult to access (Fox and Moreland 2015; Treem and Leonardi 2013), including textual or behavioural information. However, scant live streaming research deems information use by viewers as live streaming because most situations (e.g., gaming, lifestyle) mainly afford viewers' entertainment. Using TLS though, viewers are more likely to engage in information seeking especially when they intend to travel to the live streamed place. They may obtain practical and potentially real information from the travel live streamer's experience.

\subsubsection{Social engagement}

Engagement is one of the most important actions for viewers who use TLS affordances. Viewers can simultaneously watch and comment and make requests for particular TLS activities. Live streamers can receive these comments in real time and incorporate viewers' requests into their performance. This live streamer-viewer engagement produces a new level of interactive performance. Building on the theatrical analogy, viewers become the 'directors' of a performance enacted on a hybrid stage consisting of a virtual space and a physical destination. For example, in the Melbourne Remote Control Tourist campaign, viewers were able to direct travel live streamer's activities through interaction, for example, by asking them to visit a museum, taste pepper, and try different wines. In this sense, TLS offers specific affordances and action-supportive information on what viewers can do when visiting a place as well as inviting viewers to participate in the TLS production.

\subsubsection{Social presence}

Social presence is the key to viewers' digital social viewing because a sense of presence can lead to the feeling of being socially connected (Ang et al. 2018). Given its technological affordances, live streaming is one manifestation of modern sociality (Thorburn 2014) in that it operates by affording ways of being together, being on the move, or being far apart. The feeling of 'almost being there' (Mueser and Vlachos 2018) increases immersion and engagement, and enables viewers to be virtually involved in the 'surroundings' by using a digital lens. This 'transportation' of viewers can be measured by the level of presence experienced by viewers.

In TLS settings, the key for delivering a TLS is to create the proper atmospherethe feeling of being there-that allows the live streaming to be synchronised. The cues, which include real-time broadcasting, synchronous interaction with the travel live streamer, and the ability to see other viewers watching, emphasise the viewership of presence and a sense of 'being together' with other viewers. Further, when viewers participate in interaction and send specific requests to direct the actions of a live streamer, they might feel a sense of 'being there'. Such presence can be linked to digital immediacy (Bell and Lyall 2005), which highlights not only the timebound nature of the stream but also the real-time experience. Combining real-time 
broadcasting and interaction facilitates presence and extends the representation of travel. Thus, it is conceivable that cues generated in TLS will influence viewers' social presence.

\subsection{TLS sponsors}

Sponsors in TLS typically include tourism destinations, travel suppliers (e.g., airlines, hotels, cruise operators), tour operators and online travel agents (OTAs). TLS affordances enable sponsors to present place identity, that is, the associations between individual and place, which can involve sponsors using TLS to represent place and brand identity (Wang and Chen 2015).

\subsubsection{Place and brand identity}

Compared with the travel live streamer and viewer, sponsors often act as a third force in the creation of a live stream. Although live streamers play a more central and visible role, sponsors provide the environment that enables travel live streamers to produce the live stream. Indeed, the sponsor's role is not simply to provide a backdrop for travel live streamers (or TLS content), but rather, to afford them with resources to create TLS content. To continue with the theatre analogy, by controlling environmental and content parameters, sponsors serve as 'playwrights' or 'directors' of the live streaming content by presenting place identity (e.g., features or characteristics of place). For example, when a sponsor represents a tourism destination in a TLS, the destination is presented as a unique social and cultural environment. Viewers may retain personal attachment to this place from travel memories.

In the case of travel suppliers and OTAs, the emphasis is more on presenting brand identity through TLS affordances. Practical cases can exemplify brand identity as with Accor's use of TLS to promote their products (e.g., hotel rooms) and to connect with potential customers. The increasing interest of sponsors in live streaming is likely because live streaming drives media exposure and real-time interactions. Ultimately, TLS allows sponsors to collaborate with travel live streamers (e.g., particularly SMIs) to present brand identity and humanise their products to deliver much more immediate or authentic content. In the marketing and tourism domains, this can be referred to more broadly as influencer marketing (Femenia-Serra and Gretzel 2020).

\subsubsection{Performance measurement and targeting}

Performance measurement is used by tourism practitioners for work management, decision-making, and performance enhancement (Y1lmaz and Bititci 2006). It is linked to strategic goals and brings an array of outcome benefits to practitioners (Sainaghi et al. 2017). Some sponsors have begun to utilise TLS affordances to develop new performance measures and tools to target key markets. For example, during the COVID-19 pandemic, China's largest online-travel-agent, C-trip, launched their TLS service (for hotel and flight ticket booking). This effectively 
transformed the company's sales and marketing and significantly enhanced its overall performance. Sponsors can use TLS to target specific groups of tourists, such as tech-savvy tourists who tend to search for information through various platforms before travel (Femenia-Serra et al. 2019). TLS can also help sponsors to attract viewers and customize products to meet their needs.

The study next focuses on developing an affordance theory-based framework by using the affordances discussed so far. How they support participant actions and activities provides a first step to understanding how affordances play a part in TLS by determining the complex relationships among TLS participants.

\section{Developing an affordance-based TLS framework}

Building on the above discussion, this paper proposes an affordance-based theoretical framework (see Fig. 1) that links TLS affordances to participants' actions. As the framework suggests, in its environment, TLS is an artefact with affordances that enable particular actions for its participants. Hutchby (2001) argued that the affordance of technological artefacts can be categorised as functional (highlighting properties) and relational (highlighting human perceivers). The framework follows this approach by identifying TLS affordances (left side) and the potential actions enabled by these affordances for different types of TLS participants (right side). On the left side of the framework, TLS is viewed as a technological artefact and constructed phenomena composed of functional and relational aspects. The functional aspects enable, by shaping the conditions for possible action. For example, ICT includes digital devices (e.g., smart phones) while internet connectivity enables live streams to be produced outdoors to document tourism activities. Social media offer an online space and platform to share live streams. Visual media enable functionalities that

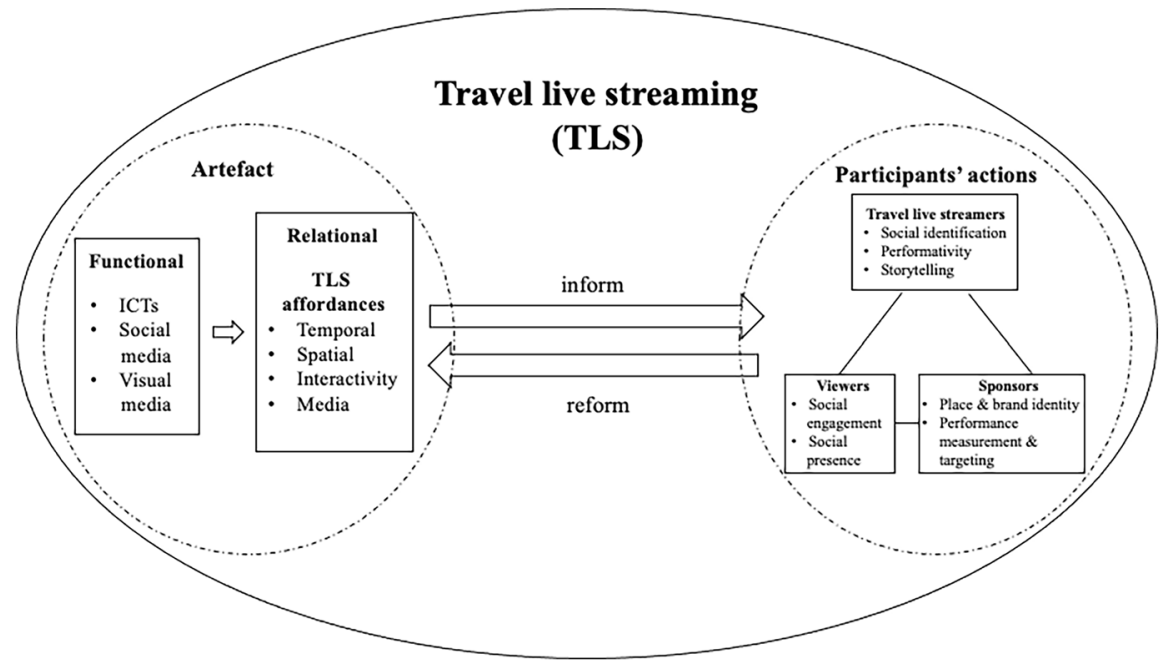

Fig. 1 Affordance-based conceptual framework of TLS 
live streams can be heard, watched, watch-produced, and spoken. The relational aspect depicts the way that affordances of an artefact can differ from one variety to another. As such, a TLS affordance is neither a technological artefact of itself nor a characteristic of live streaming, but rather an assembly of opportunities that inform participants' actions, given their own perceptions, situations, and abilities.

The right side of the framework identifies that TLS participants involve travel live streamers, viewers, and sponsors. Prior research indicates that digital technology affordances are fluid and dynamic, and opportunities can be reformed after the technology has been used by actors (Nelson et al. 2017; Yoo and Gretzel 2011). From this perspective, TLS affordances influence opportunities for particular actions though, notably, affordances of TLS can be changed after they are introduced. TLS participants can reform TLS affordances through the way they use them. For instance, the primary use of TLS is to let travel live streamers share their travel experience, wherever they are, be they fleeting moments or serendipitous ones. Participants reform the affordance of sharing by integrating storytelling, performativity, and presenting social identification.

\subsection{Propositions for future research}

Within a TLS context, travel live streamers, viewers, and sponsors play crucial roles in perceiving and using TLS affordances to support actions. Based on the identified TLS affordances and participants' perceived actions through TLS affordances, an affordance-based theoretical framework is proposed. The proposed framework triggers potential propositions for future research. Rather than merely providing a neatly framed research agenda, the derived framework presents a set of reflections and thoughts that will stimulate further TLS research. Live streaming in tourism is an intriguing means for sophisticated technology to digitise tourist experiences and influence social relationships. However, the aim is not to provide an exhaustive examination of all the potential relationships used in the framework. Within the TLS context, affordances link three groups of participants: travel live streamers, viewers, and sponsors, all of whom play vital roles in the process of TLS. Bearing this insight in mind, three propositions are presented as follows to guide future research directions:

Proposition 1 TLS affordances can help travel live streamers to construct online social identity through performance.

Future research could extend and refine the proposed framework by empirically investigating profile building affordances on social media (O'Riordan et al. 2016). For travel live streamers, every individual travel live streamer has specific abilities when exploring TLS-enabled actions. Therefore, studies could explore how travel live streamers use TLS affordances to construct social identity through self-presentation, and performance.

Social identification refers to how individuals categorise themselves as members of specific groups (Deaux 1996). Its major premise is to establish self to develop a 
sense of belonging to the community (Abrams and Hogg 1990). Social identification has been widely applied to travel-related online communities to describe how individuals construct social identities to obtain certain psychological needs (e.g. self-esteem and self-enhancement) (Qu and Lee 2011). The concept can influence interactive communication and can be linked to personal behaviour (Rather and Hollebeek 2019). This article argues that TLS affordances enable travel live streamers to establish social identity using live streaming to fashion a 'performing self'.

As mentioned earlier, TLS can be viewed as a type of performance insofar as it is characterised by temporal and spatial affordances. In contrast to gaming and lifestyle live streaming, TLS entails sharing tourism experiences as daily life. For example, when visiting museums, exploring restaurants, or strolling around the city, travel live streamers seek to perform their roles convincingly. Travel live streamers could be understood as illustrating emerging forms of technology-based sociality that generalise contemporary life. Their identities when streaming these tourism experiences are influenced by interactions, compliments or even materialistic desires, such as virtual gifts from their viewers (Yu et al. 2018).

The positions of some travel live streamers are privileged in that they act as opinion leaders and brand endorsers (Femenia-Serra and Gretzel 2020). They experiment with their social identity by using digital technology for self-branding and self-presentation. During this process, travel live streamers monitor their own performance and bodily demeanour. $\mathrm{Hu}$ et al. (2017) argued that live streaming is a personal practice associated with a live streamer's social identity to attract viewers. This raises questions about whether travel live streamers are performing their 'real' self or what they regard is an 'ideal' self? Presenting the 'real' or 'ideal' self can be associated with the question of how travel live streamers negotiate authenticity during the TLS. These questions are essential for considering how TLS influence travel live streamers' experience, which remains crucial for directing TLS design.

Further, the temporal affordances of TLS raises questions about the authentic self (Young 2013). As Wang (1999, p. 364) observed, 'tourists are not merely searching for authenticity of other, they also search for the authenticity of, and between, themselves.' The dramaturgy of Goffman (1978) considers life as a stage for activity in that an individual presents an idealised rather than an authentic self, that is, in the version that reveals both 'frontstage' and 'backstage' behaviours of self. TLS affords a travel live streamer a stage for performance. On the frontstage, the travel live streamer tries to present an idealised self to viewers, while on the backstage, much effort is expended to make the frontstage performance look more authentic. However, how live streamers negotiate and represent the self on this front stage and backstage is worthy of further exploration in the existential authenticity sense.

Proposition 2 TLS affordances can help sponsors to achieve strategic and operational goals.

For sponsors, natural landscapes, buildings, or even small restaurants provide a backdrop and a stage for TLS. From the sponsors' perspective, it might be interesting to look at how TLS affordances support the goals and actions of sponsors. 
For example, sponsors can collaborate with travel live streamers by utilising their storytelling ability to display place/brand identity.

Storytelling is a way of communicating through narratives (Pera 2017). As humans are innately story tellers, such narration is an essence of human nature (Kellert 2012). Its importance in transmitting information is acknowledged widely in the academic literature. Mossberg (2008) contended that stories engage emotions, stimulation, fantasies, and thoughts, in ways that meet psychological demand. Indeed, Coleman and Crang (2002) pointed out that tourism can be exhibited as storytelling, chatting, swapping anecdotes, and competitive tales. Tussyadiah et al. (2011) also suggested that travel stories are persuasive and thus enable audiences to visualise potential consumption.

TLS affords these storytelling values for travel live streamers. If a travel live streamer can tell a sufficiently appealing and interesting story for a collaborated sponsor, he/she provides viewers with additional meaning and insight to the place (e.g. destination history, culture). Bassano et al. (2019) proposed that place storytelling can motivate visitors, guide behaviour, create belonging and trust, and maintain memory. Although a range of channels (TV and travel blogs) are used to spread the story, these channels mostly reflect post-travel stories. Through TLS affordances, sponsors relate to present travel stories to evoke the imagination of viewers who may intend to travel, and to trigger memories of a specific place in real-time. As such, it is crucial for TLS sponsors to recognise affordances that may help them achieve strategic or operational goals (e.g., promote destinations, products, and services).

Proposition 3 TLS affordances provide viewers with new interactive virtual experiences.

There is an opportunity for further research on the role of interactivity affordances in TLS. While interaction is generally assumed to be the natural attribute of face-to-face conversation (Goffman 2017), it has also been studied in technology-mediated communication settings. Benyon et al. (2014) argued that digital interaction should contain a high level of presence because it will lead to higher psychological bonds (or social connection) (Riva et al. 2007).

The interactivity affordance of TLS provides viewers with a sense of presence, of being there and being together. Basically, the sense of being there is conveyed through the interaction between a travel live streamer and viewers (one-to-many pattern interaction), and interaction among viewers (many-to-many pattern interaction). For instance, a live streamer engages in dialogues and interactions with viewers while visiting the destination through a virtual forum where they can 'perform' for viewers and interact with them in real time. The temporal affordances of TLS enhance the level of interaction between live steamers and viewers, and among viewers (e.g., comments and virtual gifts). At an advanced level, this collective sense of being together is delivered through viewers participating in the experience by directing the live streamer's actions at the destination site. Even for those viewers who do not engage in interactions with the live streamer 
or other viewers (so called 'lurkers'), this interactivity affordance encourages social interaction by allowing viewers to build, invest in, and maintain social ties with a geographically distant travel live streamer.

\section{Conclusion}

To sum up, this paper sheds light on the novel and emerging phenomena of TLS, which has become increasingly popular and important for the tourism industry. The present study attempts to conceptualise TLS from an affordance perspective to provide an explication of what constitutes TLS. The paper identifies four distinctive affordances that enable different groups of participants (travel live streamers, viewers, and sponsors) in a TLS domain: temporal, spatial, interactivity and media affordance. These affordances provide participants with opportunities for possible actions (e.g., travel live streamers' performativity, viewers' social engagement, sponsors' place identity). Based on these, an affordance-based framework is proposed to conceptualise TLS. The conceptual framework highlights TLS affordances and the enabled actions for the major participants (travel live streamer, viewer, and sponsors). In the discussions, we proposed propositions to guide future research.

Theoretically, this paper makes several contributions. First, this study contributes to the literature on live streaming technology in tourism contexts. It is intended to offer an initial attempt to understand the TLS phenomena. Second, this seeks to understand TLS by using affordances as a theoretical lens to this area of inquiry. Affordances offer a powerful perspective for studying human-environment systems. It is also a useful approach for analysing socio-technical phenomena. This study extends prior research on social media affordances (Cabiddu et al. 2014) by exploring travel live streamers, viewers, and sponsors' goal-oriented actions in the TLS context. Third, from the affordance perspective, a conceptual framework is constructed to conceptualise TLS. This framework serves as a starting point and provides a basis for future empirical research.

Notably, this paper holds promise for future research and stimulate multidisciplinary debate about the role of live streaming in tourism. We suggest future research to explore TLS as not merely an empty practice, but rather to treat it as a theoretically distinct form of affordance that can be applied to a range of contexts, such as over-tourism and tourism disaster recovery to adapt to the continuously changing world.

\section{Declarations}

Conflict of interest The authors declare that they have no conflict of interest.

\section{References}

Abrams D, Hogg MA (1990) Social identification, self-categorization and social influence. Eur Rev Soc Psychol 1:195-228

Agger B (2011) iTime: labor and life in a smartphone era. Time Soc 20:119-136 
Ang T, Wei S, Anaza NA (2018) Livestreaming vs pre-recorded: how social viewing strategies impact consumers' viewing experiences and behavioral intentions. Eur J Mark 52:2075-2104

Baerenholdt OH, Haldrup MM, Larsen J, Urry J (2004) Performing tourist places. Ashgate, Aldershot

Bassano C, Barile S, Piciocchi P, Spohrer JC, Iandolo F, Fisk R (2019) Storytelling about places: tourism marketing in the digital age. Cities 87:10-20

Bell C, Lyall J (2005) 'I was here'-pixilated evidence. The media and the tourist imagination: converging cultures, pp 135-142

Benyon D, Quigley A, O'Keefe B, Riva G (2014) Presence and digital tourism. AI Soc 29:521-529

Blewett C, Hugo W (2016) Actant affordances: a brief history of affordance theory and a Latourian extension for education technology research. Crit Stud Teach Learn 4:55-76

Bucher T, Helmond A (2017) The affordances of social media platforms. The SAGE handbook of social media, pp 233-253

Buckley R, Akhoundogli M (2020) Tourism affordances as a research lens. J Travel Res 59:1331-1334

Buhalis D, Sinarta Y (2019) Real-time co-creation and nowness service: lessons from tourism and hospitality. J Travel Tour Mark 36:563-582

Buhalis D, Harwood T, Bogicevic V, Viglia G, Beldona S, Hofacker C (2019) Technological disruptions in services: lessons from tourism and hospitality. J Serv Manag. https://doi.org/10.1108/ JOSM-12-2018-0398

Burroughs B, Rama P (2015) The eSports Trojan horse: Twitch and streaming futures. J Virt Worlds Res $8: 1-5$

Cabiddu F, De Carlo M, Piccoli G (2014) Social media affordances: enabling customer engagement. Ann Tour Res 48:175-192

Camisón C, Monfort-Mir VM (2012) Measuring innovation in tourism from the Schumpeterian and the dynamic-capabilities perspectives. Tour Manag 33:776-789

Chen Y-S, Wu S-T (2021) An exploration of actor-network theory and social affordance for the development of a tourist attraction: a case study of a Jimmy-related theme park. Taiwan Tour Manag 82:104206

Coleman S, Crang M (2002) Tourism: between place and performance. Berghahn Books, New York

Deaux K (1996) Social identification. Guilford, New York

Dinhopl A, Gretzel U (2015) Changing practices/new technologies: photos and videos on vacation. In: Information and communication technologies in tourism 2015. Springer, pp 777-788

Dinhopl A, Gretzel U (2016) Conceptualizing tourist videography. Inf Technol Tour 15:395-410

Dux J, Kim J (2018) Social live-streaming: Twitch.TV and uses and gratification theory social network analysis. Comput Sci Inf Technol 47

Femenia-Serra F, Gretzel U (2020) Influencer marketing for tourism destinations: lessons from a mature destination. In: Information and communication technologies in tourism 2020. Springer, pp 65-78

Femenia-Serra F, Perles-Ribes JF, Ivars-Baidal JA (2019) Smart destinations and tech-savvy millennial tourists: hype versus reality. Tour Rev 74:63-81

Fesenmaier DR, Xiang Z (2017) Introduction to tourism design and design science in tourism. In: Design science in tourism. Springer, pp 3-16

Fox J, Moreland JJ (2015) The dark side of social networking sites: an exploration of the relational and psychological stressors associated with Facebook use and affordances. Comput Hum Behav 45:168-176

Gibson J (1979) The Ecological Approach to Visual Perception. LEA, Hillsdale

Goffman E (1978) The presentation of self in everyday life. Harmondsworth, London

Goffman E (2017) Interaction ritual: essays in face-to-face behavior. Routledge, New York

Haldrup M, Larsen J (2003) The family gaze. Tour Stud 3:23-46

Hilvert-Bruce Z, Neill JT, Sjöblom M, Hamari J (2018) Social motivations of live-streaming viewer engagement on Twitch. Comput Hum Behav 84:58-67

Hu M, Zhang M, Wang Y (2017) Why do audiences choose to keep watching on live video streaming platforms? An explanation of dual identification framework. Comput Hum Behav 75:594-606

Hutchby I (2001) Technologies, texts and affordances. Sociology 35:441-456

Jovicic DZ (2019) From the traditional understanding of tourism destination to the smart tourism destination. Curr Issues Tour 22:276-282

Kaytoue M, Silva A, Cerf L, Meira Jr W, Raïssi C (2012) Watch me playing, i am a professional: a first study on video game live streaming. In: Proceedings of the 21 st international conference on world wide web, 2012, pp 1181-1188 
Kellert SR (2012) Building for life: designing and understanding the human-nature connection. Island Press, Washington, DC

Larsen J (2005) Families seen sightseeing: performativity of tourist photography. Space Cult 8:416-434

Lei SI, Wang D, Law R (2019) Perceived technology affordance and value of hotel mobile apps: a comparison of hoteliers and customers. J Hosp Tour Manag 39:201-211

Leonardi PM (2012) Materiality, sociomateriality, and socio-technical systems: what do these terms mean? How are they different? Do we need them materiality and organizing: social interaction in a technological world, 25

Leung D, Law R, Van Hoof H, Buhalis D (2013) Social media in tourism and hospitality: A literature review. J Travel Tour Mark 30:3-22

Levy Y, Ellis TJ (2006) A systems approach to conduct an effective literature review in support of information systems research. Inf Sci 9:181-212

Li Y, Peng Y (2021) What drives gift-giving intention in live streaming? The perspectives of emotional attachment and flow experience. Int J Hum Comput Interact. https://doi.org/10.1080/10447318. 2021.1885224

Lim JS, Choe M-J, Zhang J, Noh G-Y (2020) The role of wishful identification, emotional engagement, and parasocial relationships in repeated viewing of live-streaming games: a social cognitive theory perspective. Comput Hum Behav 108:106327

Lo IS, McKercher B, Lo A, Cheung C, Law R (2011) Tourism and online photography. Tour Manag 32:725-731

Lu Z, Annett M, Wigdor D (2019) Vicariously experiencing it all without going outside: a study of outdoor livestreaming in China. Proc ACM Hum Comput Interact 3:1-28

Mossberg L (2008) Extraordinary experiences through storytelling. Scand J Hosp Tour 8:195-210

Mueser D, Vlachos P (2018) Almost like being there? A conceptualisation of live-streaming theatre. Int J Event Festiv Manag. https://doi.org/10.1108/IJEFM-05-2018-0030

Nelson SB, Jarrahi MH, Thomson L (2017) Mobility of knowledge work and affordances of digital technologies. Int J Inf Manag 37:54-62

Norman DA (1988) The psychology of everyday things. Basic Books, New York

O'Riordan S, Feller J, Nagle T (2016) A categorisation framework for a feature-level analysis of social network sites. J Decis Syst 25:244-262

Pera R (2017) Empowering the new traveller: storytelling as a co-creative behaviour in tourism. Curr Issues Tour 20:331-338

Qu H, Lee H (2011) Travelers' social identification and membership behaviors in online travel community. Tour Manag 32:1262-1270

Rather RA, Hollebeek LD (2019) Exploring and validating social identification and social exchangebased drivers of hospitality customer loyalty. Int J Contemp Hosp Manag 31:896-905

Recktenwald D (2017) Toward a transcription and analysis of live streaming on Twitch. J Pragmat 115:68-81

Reed ES (2014) The intention to use a specific affordance: a conceptual framework for psychology. In: Development in context. Psychology Press, pp 61-92

Riva G et al (2007) Affective interactions using virtual reality: the link between presence and emotions. CyberPsychol Behav 10:45-56

Rossi PH, Lipsey MW, Henry GT (2018) Evaluation: a systematic approach. Sage Publications, Thousan Oaks

Sainaghi R, Phillips P, Zavarrone E (2017) Performance measurement in tourism firms: a content analytical meta-approach. Tour Manag 59:36-56

Scarles C (2009) Becoming tourist: Renegotiating the visual in the tourist experience. Environ Plan D Soc Space 27:465-488

Scheibe K, Fietkiewicz KJ, Stock WG (2016) Information behavior on social live streaming services. J Inf Sci Theory Pract 4:6-20

Shaw JD, Tangirala S, Vissa B, Rodell JB (2018) New ways of seeing: theory integration across disciplines. Academy of Management, Briarcliff Manor

Sjöblom M, Törhönen M, Hamari J, Macey J (2019) The ingredients of Twitch streaming: affordances of game streams. Comput Hum Behav 92:20-28

Stets JE, Burke PJ (2000) Identity theory and social identity theory. Soc Psychol Q 63:224-237

Sun Y, Shao X, Li X, Guo Y, Nie K (2019) How live streaming influences purchase intentions in social commerce: an IT affordance perspective. Electron Commer Res Appl 37:100886 
Taylor T (2018) Watch me play: Twitch and the rise of game live streaming. Princeton University Press, Princeton

Terzidou M, Stylidis D, Terzidis K (2018) The role of visual media in religious tourists' destination image, choice, and on-site experience: the case of Tinos, Greece. J Travel Tour Mark 35:306-319

Thorburn ED (2014) Social media, subjectivity, and surveillance: moving on from occupy, the rise of live streaming video. Commun Crit/Cult Stud 11:52-63

Todd PR, Melancon J (2018) Gender and live-streaming: source credibility and motivation. J Res Interact Mark 12:79-93

Tomej K, Xiang Z (2020) Affordances for tourism service design. Ann Tour Res 85:103029

Treem JW, Leonardi PM (2013) Social media use in organizations: exploring the affordances of visibility, editability, persistence, and association. Ann Int Commun Assoc 36:143-189

Tussyadiah IP, Park S, Fesenmaier DR (2011) Assessing the effectiveness of consumer narratives for destination marketing. J Hosp Tour Res 35:64-78

Wacker JG (1998) A definition of theory: research guidelines for different theory-building research methods in operations management. J Oper Manag 16:361-385

Walker A (2014) Watching us play: postures and platforms of live streaming. Surveill Soc 12:437-442

Wang N (1999) Rethinking authenticity in tourism experience. Ann Tour Res 26:349-370

Wang S, Chen JS (2015) The influence of place identity on perceived tourism impacts. Ann Tour Res $52: 16-28$

Wongkitrungrueng A, Assarut N (2018) The role of live streaming in building consumer trust and engagement with social commerce sellers. J Bus Res. https://doi.org/10.1016/j.jbusres.2018.08.032

Wongkitrungrueng A, Dehouche N, Assarut N (2020) Live streaming commerce from the sellers' perspective: implications for online relationship marketing. J Mark Manag 36:488-518

Woodcock J, Johnson MR (2019) Live streamers on Twitch. TV as social media influencers: chances and challenges for strategic communication. Int J Strateg Commun 13:321-335

Yılmaz Y, Bititci US (2006) Performance measurement in tourism: a value chain model. Int J Contemp Hosp Manag 18:341-349

Yoo K-H, Gretzel U (2011) Influence of personality on travel-related consumer-generated media creation. Comput Hum Behav 27:609-621

Young JO (2013) Authenticity in performance. In: The Routledge companion to aesthetics. Routledge, pp 474-483

Yu E, Jung C, Kim H, Jung J (2018) Impact of viewer engagement on gift-giving in live video streaming. Telemat Inform 35:1450-1460

Zhao Q, Chen C-D, Cheng H-W, Wang J-L (2018) Determinants of live streamers' continuance broadcasting intentions on Twitch: a self-determination theory perspective. Telemat Inform 35:406-420

Zhou F, Chen L, Su Q (2019) Understanding the impact of social distance on users' broadcasting intention on live streaming platforms: a lens of the challenge-hindrance stress perspective. Telemat Inform 41:46-54

Zhu S (2020) Ctrip scores big with livestreaming sales event. Shine. https://www.shine.cn/biz/tech/20040 35652/. Accessed 1 Nov 2020

Zou S (2018) Producing value out of the invaluable: a critical/cultural perspective on the live streaming industry in China tripleC: communication capitalism and critique. Open Access J Glob Sustain Inf Soc 16:805-819

Publisher's Note Springer Nature remains neutral with regard to jurisdictional claims in published maps and institutional affiliations. 